\title{
Research Status and Prospects of Coal Seam Gas Content Prediction Based on Mathematical Model
}

\author{
Dai Linchao ${ }^{1,2, a}$ \\ ${ }^{1}$ National Key Laboratory of Gas Disaster Detecting, Preventing and Emergency Controlling, \\ Chongqing 400037, China; \\ ${ }^{2}$ Chongqing Research Institute Co., Ltd. of China Coal Technology and Engineering Group, \\ Chongqing 400037, China. \\ acumtbdlc@126.com
}

Keywords: Coal seam gas content; Prediction; Mathematical model; Research status.

\begin{abstract}
The coal seam gas content is the base of coal mine gas reserves calculation, but also is the important index to forecast the gas emission and evaluate the coal and gas outburst danger. The paper summarizes the current widely used mathematical models to predict the coal seam gas content, and focuses on the research progress of the regression analysis model, the artificial neural network model, the support vector machine models, and so on. On this basis, the shortcomings and the urgent problems of gas content prediction mathematical model were analyzed and prospected. It could provide more simple and applicable method for the coal seam gas drainage, gas emission prediction, coal and gas outburst prediction and so on.
\end{abstract}

\section{Introduction}

Coal seam gas content is an important basis for the forecast of coal seam gas emission and the calculation of gas reserves[1]. The main factors affecting coal seam gas content are: coal seam occurrence condition, coal seam buried depth, coal metamorphic grade, hydrology geology structure, surrounding rock property and so on. Currently, there are many coal seam gas content prediction research methods, such as separate source method, mine statistical method, comprehensive prediction method, mathematical model method and so on[2-3]. With the rise and rapid development of computer method and technology, more and more scholars began to establish the coal seam gas content forecast model, such as gray model, artificial neural network model, support vector machine(SVM) model, etc. In recent years, with the increase of coal mining depth, deep coal seam gas content showed different degree of increases, and it became more and more difficult to predict. Based on this, the current widely used gas content prediction mathematical models are reviewed and summarized, and the coal seam gas content prediction research was discussed.

\section{Regression Analysis Method}

Regression analysis is a commonly used method of date statistical analysis. The main purpose of this method is to understand if there is a correlation between two or more variables, establish a mathematical model to study specific variables to predict the variation regularity of formulation variables. According to the causal relationship between independent variable and dependent variable (linear or nonlinear), regression analysis method can be divided into linear regression analysis and nonlinear regression analysis.

Linear Regression Analysis: H.F. Yan(2010)[4] used linear statistical rule and gas geology factor analysis method to determine the main control factors of Peigou mine coal seam gas content, and established the Peigou mine coal seam gas content prediction model with multiple linear regression analysis method.

$$
Q=11.102+0.007 K_{1}-0.088 K_{2}-0.327 K_{3}
$$


Where, $Q$ is the gas content, $\mathrm{m}^{3} / \mathrm{t} ; \mathrm{K}_{1}$ is burial depth, $\mathrm{m}$; $\mathrm{K}_{2}$ is sand ratio, \%; $\mathrm{K}_{3}$ is chasm on the plate factors.

J.Y. Yang, ect.(2011)[5] used unary linear regression method to analyze the main factors of influencing the gas occurrence, and established gas content prediction mathematical model.

H.W. Jiang, ect.(2014)[6] found that the gas concentration prediction model between buried depth and gas content has the problem that estimated values were lower than the actual, and proposed the corresponding monadic linear regression correction model.

B.B. Gao, ect.(2015)[7] used the partial least squares multiple linear regression to get optimal mathematical model of multiple linear regression equation.

$$
\begin{aligned}
& Q=-0.3125 x_{1}+0.2412 x_{2}+0.257 x_{3}+0.0242 x_{4} \\
& -0.4235 x_{5}-0.014 x_{6}-0.1526 x_{7}+0.1787 x_{8}+0.7235 x_{9}
\end{aligned}
$$

Nonlinear Regression Analysis: Based on a certain mining area coal seam gas content and buried depth data, H.Q. Cui, etc.(2012)[8] used nonlinear regression mathematical method to establish the elliptic mathematical prediction model between the gas content and buried depth.

$$
Q=\frac{X}{(0.0195 X+15.119)}
$$

Where, $\mathrm{Q}$ is the gas content, $\mathrm{m}^{3} / \mathrm{t}$; $\mathrm{X}$ is burial depth, $\mathrm{m}$.

Based on the theory of multivariate nonlinear regression mathematical method, T.X. Hao, etc.(2014)[9] established a prediction model for the Huangling mine.

\section{Artificial Neural Network Model}

Artificial neural network is a kind of applied to the structure of the brain synapses connection to the mathematical model of information processing. And it has self-organizing, adaptive, real-time learning and other characteristics.

Taking Huainan Panyi mine 13-1 coal seam as the research object, G.M. Wu, etc.(2008)[10] studied the main factors affecting coal seam gas content of coal metamorphic degree, buried depth , coal seam thickness, roof and floor lithology and geological structure, and established the suitable gas content prediction model by using BP neural network method.

Y.J. Ma,ect.(2010)[11] selected nine characteristic indexes of Qianjiaying mine gas content by using powerful Matlab neural network toolbox, and predicted the gas content with the BP model.

According to the limitation of neural network in forecasting the coal seam gas content, such as slow convergence speed and poor reliability, the domestic and foreign scholars began to introduce other algorithms to establish the gas content predictive model combined with the neural network.

T.X. Hao, ect.(2011)[12] selected coal seam buried depth, overlying rock thickness, coal thickness, roof lithology and so on for the prediction of coal bed gas content influence variables to establish the coal bed gas content prediction model based on fuzzy neural network. Through the calculation example verification, its prediction accuracy increased $4.84 \%$ 25.79\% than the neural network model.

B. Cao, ect.(2015)[13] optimized the weight and threshold of BP neural network with the genetic algorithm, and established the PCA-GA-BP neural network prediction models of gas content. The studies showed that the average relative error of PCA - GA - BP network prediction model is $2.759 \%$, and it could predict coal bed gas content accurately.

C.X. Li, ect.(2015)[14] used the grey correlation analysis method to determine the slip distance, buried depth, bedrock thickness and volatile matter as the main geological factors, and input them to the BP neural network prediction model of coal bed gas content as the independent variables. The results showed that the average relative error of the grey theory-BP neural network model is $4.2 \%$, higher than the multivariate regression analysis. 


\section{Support Vector Machine Model}

In 1995, AT\&T bell laboratories Vapnik and his team proposed support vector machine (SVM) as the new machine learning algorithm on the basis of statistical learning theory. Support vector machine (SVM) mainly has the training error as the constraint condition of optimization problems, and minimizes the confidence limit value as optimization objective, and fully embodies the basic ideas of structural risk minimization criterion.

Combining the particle swarm optimization algorithm with the least squares support vector machine theory, A. N. Jiang, ect.(2009)[15] searched the best parameters of support vector machine, and proposed the particle swarm least squares support vector machine method to predict the gas content.

Combined with the actual measurement data, B.S. Nie, ect.(2010)[16] determined the coal thickness, the bedrock buried depth, 50m thick roof strata thickness influence coefficient as the independent variables and coal seam gas content as the dependent variable, established the coal seam gas content prediction model with the support vector machine, and analyzed the hill range coefficient, root mean square error, mean absolute percentage error compared with the artificial neural network prediction model.

Combining the cross validation method with the support vector machine, T. Liu, etc.(2015)[17] established working face gas content prediction model.

\section{Other Methods}

In addition to the above studies, other gas content prediction mathematical models are established.

Q. Ye, etc.(2006)[18] established the grey system $\operatorname{GM}(1,1)$ model to predict the coal bed gas content based on the grey system theory.

$$
q^{(1)}(k+1)=\left[q^{(0)}(1)-\frac{b}{a}\right] e^{-a k}+\frac{b}{a}=4.53987 e^{0.053837 k}
$$

F. Guo, ect.(2008)[19] selected the roof lithology, buried depth and coal seam thickness as the variables, and established the gas content prediction model based on quantification theory.

$$
Q=0.016011 x(1)+1.982698 x(2)-2.748845 \delta(1,1)-7.565900 \delta(1,2)
$$

S.X. Yin, etc.(2010)[20] built six nodes triangular element method to predict the gas content calculation model.

\section{Conclusion and Prospect}

Based on the above analysis, the regression analysis model, grey model, artificial neural network model, support vector machine model have been widely used in the coal seam gas content prediction research aspects, and have obtained certain achievements, but there are still many shortcomings.

(1) At present in the coal bed gas content prediction model, the main consideration factors affecting gas content are: the coal seam buried depth, coal seam occurrence condition, coal seam dip Angle, metamorphic degree, surrounding rock properties and so on. But with the increase of coal mining depth at an annual rate of 10 20m to extend deep, the factors affecting gas content are more and more complicated. So the future research should strengthen the selection of the factors affecting gas content and its corresponding quantitative method.

(2) Using the mathematical statistics, artificial intelligence methods to establish the gas content prediction models are based on the respective samples, but the sample data has some limitations. For example, the establishment of the neural network model must be based on the large number of samples, and when using the sample data or the representative is poorer, the neural network judgment ability is worse, and it would lead to the final prediction effect decreases, and could not reach the desired accuracy. Therefore, how to select the appropriate sample data remains to have the focus of the further research. 
(3) With the continuous increase of mining depth, the geological condition is more complex, and the deep mine coal seam gas content presented nonlinear, dynamic and random uncertainty, but the prediction model has certain limitation at the moment, and it already cannot satisfy the new requirements. Therefore, the forecast model requires constant development in the direction of multiple parameters, nonlinear. Accompanied by the rapid development of the mathematical statistics methods, artificial intelligence, it would present more and more mathematics theory and algorithm. In the future, it should draw lessons from more advanced, more reasonable theory and algorithm, or should choose the variety of methods.

(4) Through the study of coal seam gas content prediction method, it could provide more simple and applicable method for the coal seam gas drainage, gas emission prediction, coal and gas outburst prediction and so on.

\section{Acknowledgement}

This study was financially supported by National Natural Science Foundation of China (51574280), Chongqing Frontiers and Application-based Research Program (cstc2015jcyjBX0076), The Science and Technology Innovation Fund of China Coal Technology \& Engineering Group (2015ZDXM14), The Science and Technology Innovation Fund of Coal Science Research Institute (2015ZYJ002).

\section{References}

[1] L. Yuan, S. Xuan: Beijing Science Press, 2014.

[2] B.F. Yu: Beijing Coal Industry Press, 2005.

[3] W.Y. Cheng, K.J. Wang, J.G. Zhang: Mining Safety and Environmental Protection, (2000) No.5, p.20-21. (In Chinese)

[4] H.F. Yan: Zhongzhou Coal, (2010) No.7, p.6-8,19. (In Chinese).

[5] J.Y. Yang, Z.G. Long, X.M. Yang: Coal Technology, (2011) No.12, p.70-71. (In Chinese).

[6] H.W. Jiang, C.L. Jiang, J. Cao: Coal Mining Technology, (2014) No.4, p.123-125. (In Chinese).

[7] B.B. Gao, J.Y. Pan, Y.P. Liu: Journal of Henan Polytechnic University(Natural Science), (2015) No.2, p.146-150. (In Chinese).

[8] H.Q. Cui, Z.A. Zhang, D.J. Li: Journal of Henan Polytechnic University(Natural Science), (2012) No.6, p.637-640. (In Chinese).

[9] T.X. Hao, M. Liu: Coal Technology, (2014) No.9, p.1-3. (In Chinese).

[10] G.M. Wu, M. Huang, G. Li: Coal Geology and Exploration, (2008) No.1, p.30-33. (In Chinese).

[11] Y.J. Ma, G.G. Cheng, D.Y. Zhao: Coal Engineering, (2010) No.1, p.117-119. (In Chinese).

[12] T.X. Hao, C. Song: China Safety Science Journal, (2011) No.8, p.36-41. (In Chinese).

[13] B.Cao, G. Bai, H. Li: Journal of Safety Science and Technology, (2015) No.5, p.84-90. (In Chinese).

[14] C.X. Li, G.Y. Wei: Coal Technology, (2015) No.5, p.128-131. (In Chinese).

[15] A.N Jiang, B. Liang, J. Zhang: Journal of Liaoning Technical University(Natural Science), (2009) No.3, p.363-366. (In Chinese).

[16] B.S. Nie, L.C. Dai, A.H. Yan: China Safety Science Journal, (2010) No.6, p.28-32. (In Chinese).

[17] T. Liu, J.Z. Jia: World Sci-Tech R and D, (2015) No.2, p.147-150. (In Chinese). 
[18] Q. Ye, B.Q. Lin: Mining Industry, (2006) No.7, p.28-30. (In Chinese).

[19] F. Guo, T.X. Hao: China Coal, (2008) No.11, p.84-87. (In Chinese).

[20] S.X. Yin, X.Y. Meng, F.Q. Qin: Journal of Henan Polytechnic University(Natural Science), (2010) No.2, p.140-146. (In Chinese). 